\title{
AdVANCED MeTHODS FOR Job SHOP SCHEDULING
}

\author{
Buchmeister, B.; PAlcic, I.; PAVlinjeK, J. \& Polajnar, A.
}

Abstract: The purpose of the chapter is to present scheduling principles, advanced tools, and examples of innovative scheduling systems studied in operations research and industrial engineering. It includes examples that use innovative techniques as well as academic research results that can be used to improve real-world production scheduling. The range of the concepts, techniques, and applications discussed should provide practitioners with useful tools to improve production scheduling in their own companies.

Scheduling represents the allocation of scarce sources to the tasks in definite period of time with the goal of optimization of one or more criteria. Selected scheduling procedures are represented: priority (dispatching) rules, filtered beam search and constraint-guided heuristic search. By highlighting scheduling methods and their development we suggest that researchers should focus more on the real-world production scheduling systems that still need improvement.

Key words: production planning and control, scheduling, priority rules, filtered beam search, constraint-guided heuristic search
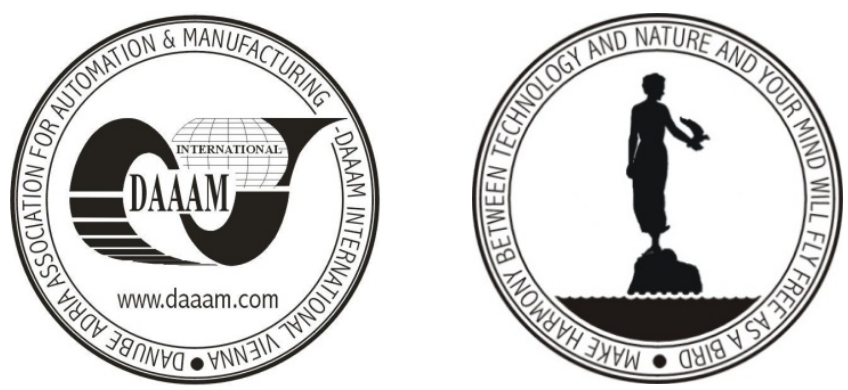

Authors' data: Prof. Buchmeister, B[orut]*; Ass. Prof. Palcic, I[ztok]*; Pavlinjek, J[oze $]^{* *}$; Prof. Dr. Polajnar, A[ndrej] ${ }^{*}$, ${ }^{*}$ University of Maribor, Faculty of Mechanical Engineering, Smetanova ulica 17, 2000 Maribor, Slovenia, **INOKS d.o.o., Goricka ulica 150, 9000 Murska Sobota, Slovenia, andrej.polajnar@uni-mb.si, borut.buchmeister@uni-mb.si, iztok.palcic@uni-mb.si,jp@inoks.si

This Publication has to be referred as: Buchmeister, $\mathrm{B}$ [orut]; Palcic, I[ztok]; Pavlinjek, J[oze] \& Polajnar, A[ndrej] (2008). Advanced Methods for Job Shop Scheduling, Chapter 15 in DAAAM International Scientific Book 2008, pp. 171-184, B. Katalinic (Ed.), Published by DAAAM International, ISBN 978-3-901509-66-7, ISSN 1726-9687, Vienna, Austria

DOI: $10.2507 /$ daaam.scibook.2008.15 